\title{
Dynamic Power System Security Analysis Using a Hybrid PSO-APO Algorithm
}

\author{
Kiran Teeparthi \\ Department of Electrical Engineering \\ National Institute of Technology Warangal \\ Warangal, India \\ kiran.t39@gmail.com
}

\author{
D. M. Vinod Kumar \\ Department of Electrical Engineering \\ National Institute of Technology Warangal \\ Warangal, India \\ vinodkumar.dm@gmail.com
}

\begin{abstract}
In this paper, a novel hybrid particle swarm optimization and artificial physics optimization (HPSO-APO) algorithm is proposed to solve the dynamic security constrained optimal power flow (DSCOPF) problem for enhancing system security. The dynamic security assessment deals with contingency analysis which is carried out using a performance index. DSCOPF recommends preventive control actions like generator rescheduling to alleviate an existing credible contingency in the system while ensuring minimal operating cost. The OPF problem is a highly nonlinear differential one and becomes more complex when considering the rotor dynamics of the system. The APO algorithm has the capability to reach a near global optimum value. However, it suffers from convergence problem. On the other hand, PSO exhibits premature convergence characteristics, but it may get trapped at a local optima value. The proposed HPSO-APO algorithm combines both individual algorithm strengths, to get balance between global and local search capability. The proposed method has been evaluated on a standard IEEE six-generator, 30-bus system and a New England ten-generator, 39-bus test system. The proposed HPSO-APO algorithm gives an efficient and robust optimal solution of DSCOPF problem compared to standard PSO and APO methods.
\end{abstract}

Keywords-dynamic security assessment; overload alleviations; security enhancement; hybrid evolutionary algorithm; stability limits.

\section{INTRODUCTION}

Power system security assessment and enhancement are two major concerns in the energy management centers (EMC) [1]. Whenever a system is subjected to sudden disturbances (e.g. line outages or generator outages or short circuit faults), it can be lead to an insecure state. Security assessment is the analysis carried out to determine the level in which a power system is safe from unforeseen disturbances (contingencies). The bottleneck of the security assessment is contingency analysis. It accesses the impact of a set of contingencies and identifies potential harmful contingencies that cause operating limit violations. Security Constrained Optimal Power Flow (SCOPF) enhances system security by implementing the preventive or corrective control actions like generation rescheduling, phase shifter positions, switching of FACTS devices, HVDC line MW transfer and load shedding during the contingencies so that no contingencies will result to violations. Power system security is classified into static and dynamic security. Static security detects any overloading lines or out of limit voltages following a given list of contingencies. Dynamic security evaluates the system dynamic behaviour in terms of transient stability or voltage stability when subjected to perturbations [2]. To illustrate the transient dynamic behavior of the system, a large group of nonlinear differential algebraic equations is involved. These equations are solved by approximate or full simulation algorithms like numerical integration methods e.g. Runge-Kutta, Euler methods or direct methods such as LyapuNov method [3-4]. The overall architecture of the DSCOPF problem is shown in Figure 1.

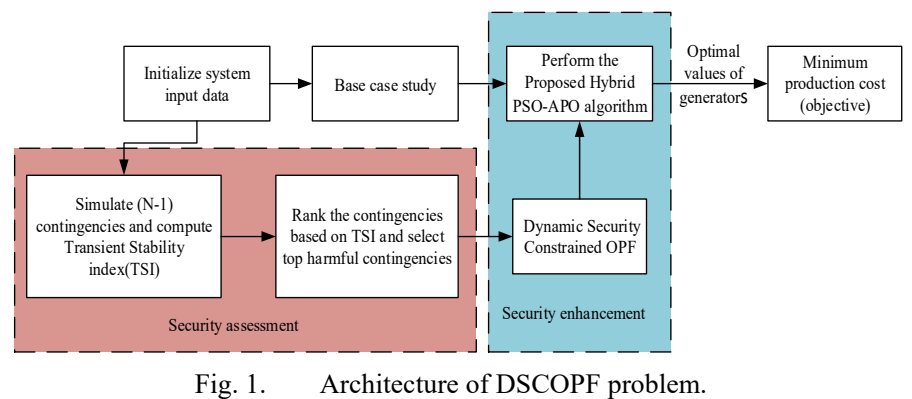

In static SCOPF problem, the dynamic constraints like rotor angle limits are excluded. Moreover, the base case of optimal power generations may or may not be able to sustain the transient stability when the system is in contingency condition. DSCOPF is a highly nonlinear differential OPF problem because of generator rotor angle dynamics. It aims to reschedule the generator active power outputs to bring back the system to the normal operating state under the consideration of static and dynamic constraints. The main challenge to solve the DSCOPF problem is choosing an effective optimization algorithm. Over the last years, various conventional (mathematical based) algorithms have been implemented to solve the OPF problem [5-6], however, these methods could be trapped at local optima solutions and also lack in handling the inequality constraints. In recent years, many researchers have tended to apply several heuristic methods for solving the OPF and transient stability OPF (TSOPF) problems like simulated 
annealing (SA) [7], genetic algorithm (GA) [8], differential evolution algorithm (DEA) [9-10], evolutionary programming method (EP) [11], particle swarm optimization (PSO) [12-13], ant colony optimization (ACO) [14], improved group search optimization (IGSO) [15], chaotic artificial bee colony (CABC) [16] and grey wolf optimization method [17]. However, these algorithms have some limitations regarding convergence issues and optimal setting of control parameters. As a way to cope with these drawbacks, hybrid heuristic optimization methods are implemented in practical and academic problems. The best results are found with hybrid methods [18-20]. A hybrid TS/SA optimization method has been implemented for solving the OPF problem using FACTS devices in [21]. A new fuzzy adaptive artificial physics optimization algorithm (FAAPO) has been proposed for solving the SCOPF problem with the wind and thermal generators [22]. A novel hybrid particle imperialist competitive algorithm and teaching learning algorithm (HICATLA) is proposed to solve the OPF problem with nonsmooth cost functions [23]. In [24], a modified TLA algorithm is implemented to solve the optimal dispatch reactive power problem. The main aim of heuristic optimization algorithms is to balance the exploitation and exploration capabilities in order to find an optimum solution with faster convergence. Some algorithms were good at exploiting but may be trapped at the local minimum point. Some are good at global search but poor in convergence.

The main contribution of this paper is to formulate a novel hybrid optimization algorithm with combining standard PSO and APO (HPSO-APO) algorithms to solve the DSCOPF problem. The standard PSO method may trap at local minima and fails to reach near global optimum value whereas APO gives the near optimal value due to its strong searching ability. However, it exhibits poor convergence characteristics. The proposed hybrid PSO-APO algorithm combines both individual algorithm strengths to get balance between exploration and exploitation. The APO algorithm improves the diversity in the search space of the PSO algorithm so as to avoid trapping in local optima. The validity of the proposed HPSO-APO method is tested on well-known standard IEEE test systems.

\section{MATHEMATICAL FORMULATION}

Dynamic security constrained OPF is a special type of OPF problem to minimize the objective function subjected to static and dynamic constraints by choosing the optimal control variables like phase-shifter angles, active and reactive power generations, transformer tap positions and voltages at PV buses. The general mathematical equation of objective function subject to the constraints is as follows:

$$
\operatorname{Min} \tilde{f}(\bar{x}, \bar{u})
$$

$$
\text { Subject to } E(\bar{x}, \bar{u})=0
$$

$$
I(\bar{x}, \bar{u}) \leq 0
$$

where, $\tilde{f}(\bar{x}, \bar{u})$ represents the objective function, $E(x, u)$ and $I(x, u)$ are two nonlinear equality and inequality constraints. The vector $x$ consists of active powers for all generators except the ref/slack bus and vector $u$ consists of all dependent variables like slack bus real power, reactive power generations, and load bus voltages. Minimization of fuel cost $\left(\mathrm{F}_{\text {cost }}\right)$ subjected to network static and dynamic constraints is the main aim of DSCOPF and it is expressed as follows [16].

$$
\text { Fuel cost }\left(F_{\text {cost }}\right)=\sum_{i=1}^{N_{g}} a_{i} P_{g i}^{2}+b_{i} P_{g i}+c_{i} \$ / h \quad ; i=1,2 \ldots \ldots N_{g}(4)
$$

where $P_{g i}$ is the real power generation of the $i^{\text {th }}$ generator, $\mathrm{N}_{\mathrm{g}}$ is the available generators, and $\mathrm{a}_{\mathrm{i}}, \mathrm{b}_{\mathrm{i}}$ and $\mathrm{c}_{\mathrm{i}}$ are the generator fuel cost coefficients. DSCOPF problem includes both static as well as dynamic constraints like generator rotor angle limits. The equality and inequality constraints for DSCOPF problem is elucidated in the following subsections [16].

\section{A. Equality Constraints (Static and Dynamic)}

The basic power flow equations give voltage magnitude and phase angle at each bus which is given by (5) and (6).

$$
\begin{aligned}
& \left(P_{\text {gen }, i}-P_{\text {load }, i}\right)-\left|V_{i}\right| \sum_{k=1}^{N_{b}}\left|V_{k}\right|\left|Y_{i k}\right| \cos \left(\delta_{i k}-\theta_{i k}\right)=0 \\
& \left(Q_{\text {gen }, i}-Q_{\text {load }, i}\right)-\left|V_{i}\right| \sum_{k=1}^{N_{b}}\left|V_{k}\right|\left|Y_{i k}\right| \sin \left(\delta_{i k}-\theta_{i k}\right)=0
\end{aligned}
$$

where $V_{i}$ and $V_{k}$ represent bus voltage magnitudes, $P_{\text {gen, } i}$ and $\mathrm{Q}_{\mathrm{gen}, \mathrm{i}}$ are specified as the real and reactive power generation of $\mathrm{i}^{\text {th }}$ bus, $\mathrm{P}_{\text {load, } \mathrm{i}}$ and $\mathrm{Q}_{\text {load,i }}$ are the real and reactive power loads of $\mathrm{i}^{\text {th }}$ bus, $\mathrm{N}_{\mathrm{b}}$ represents total number of buses, $\delta_{\mathrm{ik}}$ and $\theta_{\mathrm{ik}}$ are Voltage and admittance phase angles between i-k buses, and $Y_{i k}$ is the bus admittance matrix. In this work, a classical generator model has been considered. It comprises a constant voltage source in series with a transient. The swing equation of $i^{\text {th }}$ generator is expressed as follows [25]:

$$
\frac{2 H_{i}}{w_{s}} \frac{d^{2} \delta_{i}}{d t^{2}}=P_{m i}-P_{e i} \quad i=1,2 \ldots \ldots N_{g}
$$

where, $\mathrm{H}_{\mathrm{i}}$ is the inertia constant of $\mathrm{i}^{\text {th }}$ generator, $\mathrm{w}_{\mathrm{s}}$ is the angular speed, $\delta_{\mathrm{i}}$ is the load angle, $\mathrm{P}_{\mathrm{ei}}$ is the electrical power output, and $\mathrm{P}_{\mathrm{mi}}$ is the mechanical power input of $\mathrm{i}^{\text {th }}$ generator. During the fault condition, the electrical output power $\left(P_{e i}^{f}\right)$ is expressed in (8) and state space variable model for each generator is given in below:

$$
\begin{aligned}
& P_{e i}^{f}=\sum_{i=1}^{N_{g}}\left|E_{i}^{\prime}\right|\left|E_{j}^{\prime}\right|\left|Y_{i j}\right| \cos \left(\delta_{i j}-\theta_{i j}\right) \quad ; i=1,2 \ldots \ldots N_{g}(8) \\
& x_{1}\left(=\delta_{i}\right) \\
& x_{2}\left(=\Delta \omega_{i}\right)=\omega_{r, i}-\omega_{s} \\
& \dot{x}_{1}=\dot{\delta}_{i}=\Delta \omega_{i}=\omega_{r, i}-\omega_{s} \\
& \dot{x}_{2}=\Delta \dot{\omega}_{i}=\frac{\pi f_{o}}{H_{i}}\left(P_{m i}-P_{e i}^{f}\right)
\end{aligned}
$$

where, $\mathrm{x}_{1}\left(=\delta_{\mathrm{i}}\right)$ and $\mathrm{x}_{2}\left(=\Delta \omega_{\mathrm{i}}\right)$ represent the state variables, $\Delta \omega_{\mathrm{i}}$ is the difference between the rotor speed $\omega_{\mathrm{r}, \mathrm{i}}$ and synchronous 
speed $\left(\omega_{\mathrm{s}}\right)$ of the $\mathrm{i}^{\text {th }}$ generator. The modified Euler method is implemented to solve the state space equations because of its simplicity.

\section{B. Inequality Constraints (Static and Dynamic)}

The lower and upper limits of each element of power system inequality static and dynamic constraints are expressed as follows:

$$
\begin{array}{ll}
P_{g i}^{\min } \leq P_{g i} \leq P_{g i}^{\max } & i=1,2 \ldots \ldots N_{g} \\
S_{i} \leq S_{i}^{\max } & i=1,2 \ldots \ldots N_{\text {line }} \\
V_{i}^{\min } \leq V_{i} \leq V_{i}^{\max } & i=1,2 \ldots \ldots N_{b} \\
Q_{g i}^{\min } \leq Q_{g i} \leq Q_{g i}^{\max } & i=1,2 \ldots \ldots N_{g} \\
T_{i}^{\min } \leq T_{i} \leq T_{i}^{\max } & i=1,2 \ldots \ldots N_{T F} \\
\left|\delta_{i+1}-\delta_{1}\right|_{\max } \leq \delta_{\max } & i=1,2 \ldots \ldots\left(N_{g}-1\right)
\end{array}
$$

Generally, a penalty function approach is used for solving the constrained optimization problem. The optimization problem is converted into unconstrained one from constrained problem by penalizing the equality and inequality constraints and building a single fitness function which is given in (16).

$$
\begin{array}{r}
\operatorname{Min} \tilde{f}(x, u)=F_{\cos t}+\lambda \sum_{i=1}^{N e q}\left(E_{j}(\bar{x})^{2}\right)+\lambda\left[0, I_{j}(x, u)^{2}\right] \\
; \text { for } \mathrm{j}=1,2 \ldots . ., N_{\text {inequal }}
\end{array}
$$

where $\mathrm{E}_{\mathrm{i}}(\mathrm{x}, \mathrm{u})$ and $\mathrm{I}_{\mathrm{j}}(\mathrm{x}, \mathrm{u})$ represent static and dynamic equality and inequality constraints, $\lambda$ is the penalty factor and the value has considered as 1000 .

\section{Dynamic Security Assessment (DSA)}

The dynamic contingency analysis plays a vital role in DSA. The contingency ranking and selection has been done based on performance index [26-28] and identify the top harmful contingencies based on transient stability index (TSI). The dynamic contingency eVolution has been done by Euler's method. The TSI is defined by

$$
\mathrm{TSI}=\left[\frac{\left(360-\delta_{\max }\right)}{\left(360+\delta_{\max }\right)}\right] \times 100 ;-100<\mathrm{TSI}<100
$$

where, $\delta_{\max }$ is the maximum allowable relative rotor angle and its value is fixed based on operational experience. For a realworld power system, the $\delta_{\max }$ value is set to $100-120^{\circ}$.

\section{PROPOSED HYBRID PSO-APO ALGORITHM TO SOLVE DSCOPF PROBLEM}

The APO and PSO methods are two optimization methods inspired by basic physics and the behavior of bird flocking respectively. In PSO method, each bird is treated as the particle and each particle having its own position, velocity and fitness value [29]. Similarly, in APO, each particle constitutes mass, position, and velocity. Based on the attractive and repulsive forces, each particle tends to larger masses close to global solution [30]. In recent years, hybrid heuristic optimization methods are implemented in practical and academic problems. A classifications of hybrid optimization methods is presented in
[31]. According to [31], hybridization can be done at a low or a high level with relay or teamwork with heterogeneous or homogeneous approaches. In this paper, a low level with teamwork heterogeneous approach is used. The proposed hybrid algorithm combines both individual algorithm strengths, to get balance between global and local search capability. The general steps involved in finding the optimum values of generations subject to static as well as dynamic constraints are shown in Figure 2. The following steps are implemented to solve the DSCOPF problem by the HPSO-APO algorithm.

Step 1: (a) First, read the input data of DSCOPF problem.e., line data, bus data, and generator limits. Also, initialize the APO and PSO control parameters.

(b) Generate an initial population randomly within the given search space.

Step 2: Compute the fitness for each particle using (16) and update the best and worst values.

Step 3: Evaluate mass $\left(\mathrm{m}_{\mathrm{i}}(\mathrm{t})\right)$ and calculate the total force $\left(\mathrm{F}_{\mathrm{i}}(\mathrm{t})\right)$ on each particle iteratively using APO algorithm.

$$
\begin{aligned}
& m_{i}(t)=\exp \left(\frac{\operatorname{best}(t)-f i t_{i}(t)}{\operatorname{worst}(t)-\operatorname{best}(t)}\right) \\
& F_{i j}(t)=\left\{\begin{array}{l}
G m_{i}(t) m_{j}(t)\left(x_{j}(t)-x_{i}(t)\right) \text {; if } f i t_{j}(t)<f i t_{i}(t) \\
-G m_{i}(t) m_{j}(t)\left(x_{j}(t)-x_{i}(t)\right) ; \text { if } f i t_{j}(t)>f i t_{i}(t)
\end{array}\right. \\
& F_{i}(t)=\sum_{j \in \text { best }, j \neq i}^{p o p} F_{i j}(t)
\end{aligned}
$$

Step 4: Update particle's velocity and positions iteratively. The modified velocity equation of PSO is as follows. Finally, the positions of all particles are updated by using (22).

$$
\begin{gathered}
\begin{array}{c}
v_{i}(t+1)=w * v_{i}(t) \\
+C_{1}^{\prime} * \operatorname{rand}() *\left(F_{i}(t) / m_{i}(t)\right) \\
+C_{2}^{\prime} * \operatorname{rand}() *\left(\text { gbest }-x_{i}(t)\right)
\end{array} \\
x_{i}(t+1)=x_{i}(t)+v_{i}(t+1)
\end{gathered}
$$

Step 5: Check for maximum iterations count. If yes print the final results (fuel cost and active power generations) otherwise go to step 2 .

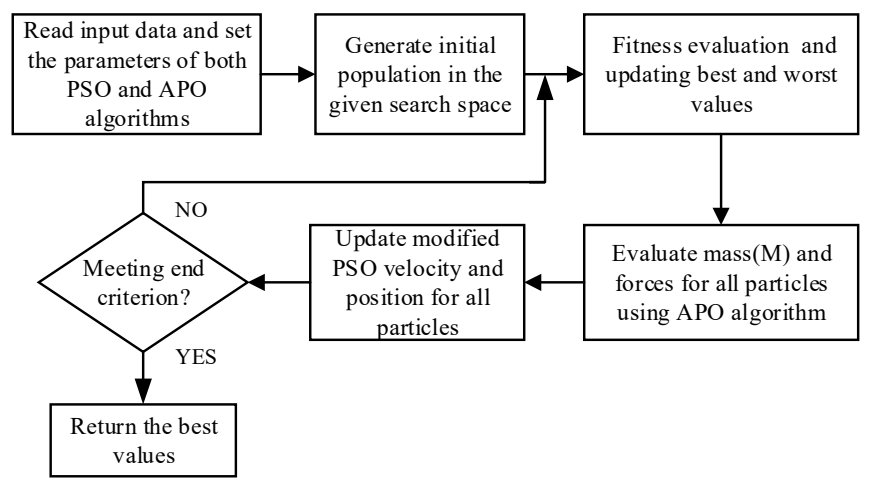

Fig. 2. Flowchart of the proposed hybrid PSO-APO algorithm. 


\section{SIMULATION RESULTS AND DISCUSSION}

In order to analyze the effectiveness of the proposed hybrid PSO-APO method, the standard IEEE six generator, 30-bus system and the New England ten generator, 39-bus system were considered. The obtained test results are compared with standard individual APO and PSO methods. The total simulation time is $3.0 \mathrm{~s}$ for observing generator rotor oscillations and the time step adopted is $0.01 \mathrm{~s}$. For each case 20 independent trail runs are performed to validate the effectiveness of the proposed hybrid algorithm. The proposed HPSO-APO algorithm is coded in MATLAB environment and all simulations were run on an Intel, Core i5-4210U processor, and $2.40 \mathrm{GHz}$ personal computer. The following case studies are considered to evaluate the robustness of HPSO-APO algorithm.

\section{(a) Base case and}

(b) (N-1) contingency cases

In the first case i.e. base case, the proposed hybrid optimization algorithm is employed to reschedule the active power generations under Normal conditions. In the next case i.e. $(\mathrm{N}-1)$ contingency case, the proposed method is utilized to solve the DSCOPF problem to alleviate the line overloads by taking preventive control action like generator rescheduling. The control parameters used for the standard APO and PSO are listed in Table I. The simulation results for both base case and contingency cases are elaborated in the following sub-sections.

TABLE I. CONTROL PARAMETERS OF APO AND PSO

\begin{tabular}{|c|c|}
\hline APO & PSO \\
\hline Population size $=50 ;$ & Swarm size $=50 ;$ \\
Max. iteration number $=100$ & Max. iteration number $=100$ \\
Gravitational constant $(\mathrm{G})=0.01$ & $\begin{array}{c}\text { Acceleration constants, } \mathrm{C} 1=\mathrm{C} 2=2 ; \\
w=1\end{array}$ \\
\hline
\end{tabular}

\section{A. IEEE 30-Bus System}

The test data (line data, bus data and generator limits) along with network topology are taken from [32]. The test system comprises of six-generators and 41 transmission lines. The total real power demand on the system is $189.2 \mathrm{MW}$.

\section{1) Case A: Base Case}

The results for the base case that are obtained by using the proposed hybrid and APO, and PSO methods are shown in Table II. The optimal fuel cost attained by the proposed hybrid method is $576.62 \$ / \mathrm{h}$. Figure 3 shows the comparison convergence characteristic. The results reveal that PSO algorithm was trapped at local optimum point, however, exhibits faster convergence characteristic. Whereas APO attains the near global optimum point, but exhibits poor convergence characteristic. The proposed hybrid optimization method was superior and robust compared to APO and PSO algorithms in terms of getting near global optimum point and faster convergence.

\section{2) Case B: (N-1) Contingency Case}

A set of contingency scenarios are created by implementing three phase short circuit faults at each bus on the system. The dynamic security assessment was done on the basis of transient stability index (TSI) [28], which is determined by TimeDomain simulation. The top-ranked contingency scenarios are listed in Table III.

TABLE II. IEEE 30-BUS SYSTEM: OPTIMAL GENERATION (MW) FOR BASE CASE

\begin{tabular}{|c|c|c|c|}
\hline $\begin{array}{c}\text { Generator bus } \\
\text { number }\end{array}$ & $\begin{array}{c}\text { Proposed hybrid } \\
\text { method }\end{array}$ & APO & PSO \\
\hline G1 & 43.69 & 44.03 & 33.24 \\
\hline G2 & 58.16 & 58.61 & 48.73 \\
\hline G13 & 17.62 & 18.17 & 12.80 \\
\hline G22 & 23.21 & 23.34 & 24.75 \\
\hline G23 & 16.76 & 15.98 & 17.94 \\
\hline G27 & 32.69 & 32.00 & 55.00 \\
\hline Fuel cost $(\$ / h)$ & 576.62 & 576.73 & 577.32 \\
\hline CPU time $(\mathrm{s})$ & 48.90 & 49.20 & 58.20 \\
\hline
\end{tabular}

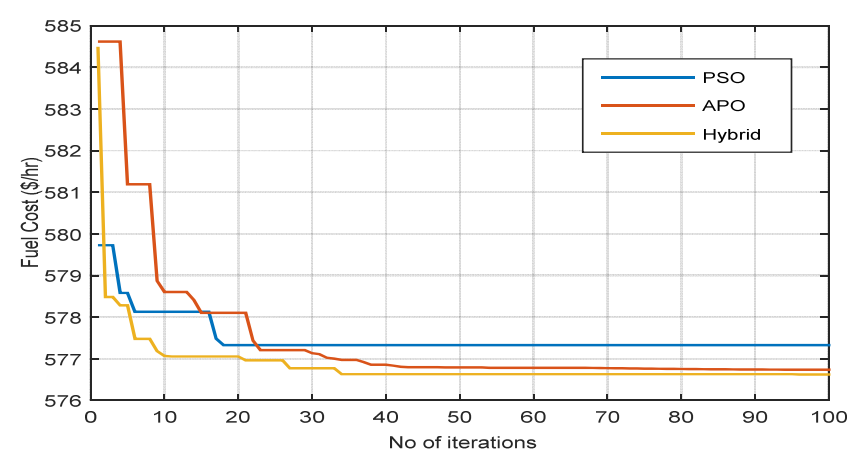

Fig. 3. Convergence characteristic of base case for 30-bus system.

The thermal and voltage limits are considered as $120 \%$ and $\pm 5 \%$ of the base case values respectively. The $\delta_{\max }$ value is set to $120^{\circ}$. The proposed optimization algorithm is implemented to solve the DSCOPF problem with preventive control actions like generator rescheduling to bring the system into normal operating conditions. The relative rotor generator angles with respect to ref/slack generator obtained by the proposed hybrid method are shown in Figures 4(a), 4(b). It is revealed that the relative rotor angles have not violated their maximum allowable limits after the rescheduling of active power generations. Hence it can be said that the system is dynamically secured during the various contingency scenarios. The fuel costs along with optimal active powers obtained by the proposed as well as other reported methods are shown in Table IV. Only the top two severe contingency cases are presented in detail. The fuel cost of thermal generators obtained by the proposed hybrid optimization method for a line outage between buses $1-2$ and $2-5$ are $603.90 \$ / \mathrm{h}$ and $593.98 \$ / \mathrm{h}$ respectively. The proposed method gives a better global optimal fuel cost than the standard APO and PSO methods. The comparison of convergence characteristics of the proposed hybrid PSO-APO algorithm, as well as for other reported algorithms for line outage between buses 1-2 and 2-5, is shown in Figures 5 and 6 . The CPU times for completion of hundred iterations are listed in Tables II and IV. The computational time of the HPSO-APO is faster than APO and PSO methods. Hence, the proposed hybrid optimization method is superior and more robust than the standard APO and PSO algorithms in terms of getting near global optimum point and faster convergence. The performance 
measure (mean and standard deviation) and statistical (Pvalues) results obtained over 20-independent runs by the proposed as well as standard APO and PSO algorithms are shown in Table V. The P-values are obtained from Wilcoxon's rank sum test. The results indicate that the proposed HPSOAPO algorithm achieves the statistically best final accuracy over standard algorithms.
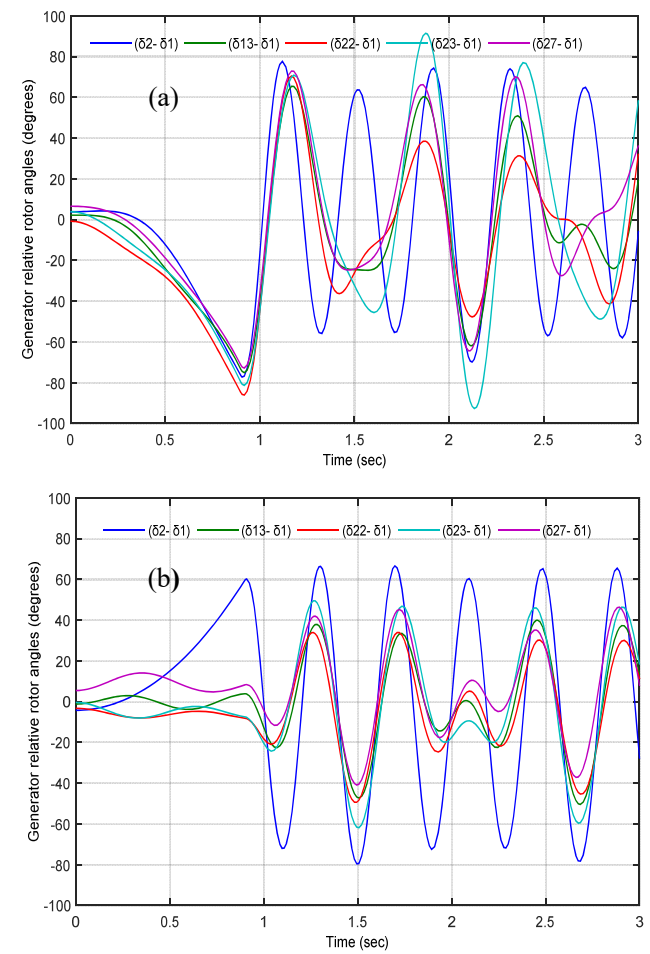

Fig. 4. Generator relative rotor angles for 30-bus system - proposed hybrid algorithm (a) Contingency-1 (between buses 1-2) (b) Contingency-2 (between buses 2-5).

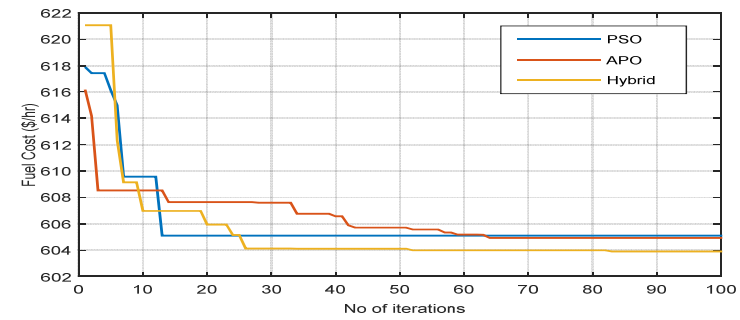

Fig. 5. Convergence characteristic of contingency-1 (between buses 1-2) for 30-bus system.

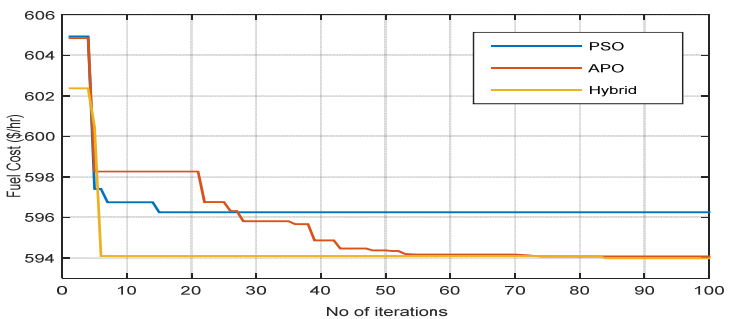

Fig. 6. Convergence characteristic of contingency-2 (between buses 2-5) for 30-bus system.
TABLE III. DYNAMIC CONTINGENCY RANKING FOR 30-BUS SYSTEM

\begin{tabular}{|c|c|c|c|}
\hline $\begin{array}{c}\text { Faulted bus } \\
\text { number }\end{array}$ & $\begin{array}{c}\text { Line outage } \\
\text { between buses }\end{array}$ & $\begin{array}{c}\text { Transient Stability } \\
\text { Index (TSI) }\end{array}$ & Rank \\
\hline 1 & $1-2$ & -87.62 & 1 \\
\hline 2 & $2-5$ & -87.18 & 2 \\
\hline 27 & $27-29$ & -85.32 & 3 \\
\hline 23 & $15-23$ & -10.60 & 4 \\
\hline 22 & $10-22$ & -7.67 & 5 \\
\hline
\end{tabular}

TABLE IV. IEEE 30-BUS SYSTEM: OPTIMAL RESCHEDULING OF GENERATION (MW) FOR CONTINGENCY CASE

\begin{tabular}{|c|c|c|c|c|c|c|}
\hline \multirow{2}{*}{$\begin{array}{c}\text { Generator bus } \\
\text { number }\end{array}$} & \multicolumn{6}{|c|}{ Line outage between buses } \\
\cline { 2 - 7 } & $\begin{array}{c}\text { Proposed } \\
\text { Hybrid method }\end{array}$ & \multicolumn{2}{|c|}{ APO } & \multicolumn{2}{c|}{ PSO } \\
\cline { 2 - 7 } & $1-2$ & $2-5$ & $1-2$ & $2-5$ & $1-2$ & $2-5$ \\
\hline G1 & 10.80 & 45.39 & 10.58 & 46.46 & 10.51 & 63.83 \\
\hline G2 & 65.33 & 30.71 & 74.94 & 30.55 & 68.91 & 12.66 \\
\hline G13 & 24.15 & 24.08 & 21.35 & 25.44 & 20.44 & 22.04 \\
\hline G22 & 26.50 & 25.79 & 25.47 & 25.64 & 24.40 & 43.12 \\
\hline G23 & 21.76 & 20.43 & 20.36 & 22.31 & 26.36 & 6.55 \\
\hline G27 & 43.28 & 45.67 & 39.16 & 41.60 & 41.33 & 44.05 \\
\hline Fuel cost (\$/h) & 603.90 & 593.98 & 604.92 & 594.07 & 605.10 & 596.25 \\
\hline CPU time (s) & 103.2 & 105.7 & 112.5 & 113.9 & 123.8 & 125.6 \\
\hline
\end{tabular}

\section{B. New England 39-Bus System}

The line data, bus data, and generator limits along with network topology are taken from [16]. The system comprises 10-generators, 46-transmission corridors, and 29-load buses. The total load on the system is $6098.0 \mathrm{MW}$. The $\delta_{\max }$ value is considered as $120^{\circ}$.

\section{1) Case A: Base case}

The optimal active power generations along with fuel costs for the proposed hybrid as well as standard APO and PSO methods are shown in Table VI. As shown, the proposed HPSO-APO algorithm outperforms the APOS and PSO algorithms and gives a fuel cost of $60917.68 \$ / \mathrm{h}$. The convergence characteristic of the best trail for the three algorithms is shown in Figure 7. The results reveal that the proposed method provides better results in terms of reaching near global optimum point and faster convergence characteristic when compared to standard individual algorithms like PSO and APO.

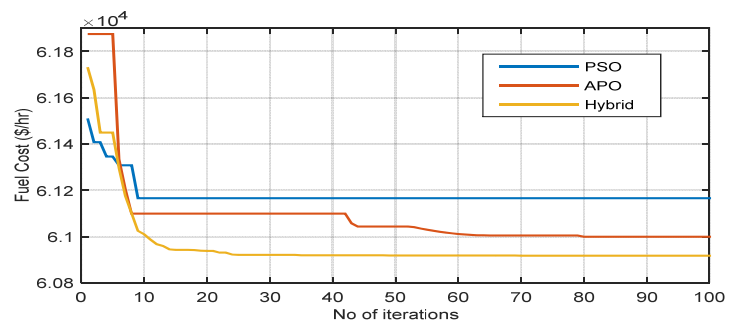

Fig. 7. Convergence characteristic of base case for 39 bus system.

2) Case B: (N-1) Contingency case

The HPSO-APO algorithm is employed for the DSCOPF problem by rescheduling generators to minimize the severity during contingency conditions. The contingency ranking is 
based on TSI using T-D simulations and the five top ranked harmful contingencies are listed in Table VII. The optimal values of active power generations along with fuel costs are shown in Table VIII. The minimum fuel cost obtained by HPSO-APO for line outage between buses 17-27 and 4-5 are $60964.60 \$ / \mathrm{h}$ and $61151.16 \$ / \mathrm{h}$ respectively. The active power generations of all generators are rescheduled subjected to system static and dynamic constraints. The results reveal that the proposed HPSO-APO algorithm achieves a near-optimal value when compared to the standard PSO and APO algorithms. The relative rotor generator angles are shown in Figure 8.

TABLE V. IEEE 30-BUS SYSTEM: PERFORMANCE AND STATISTICAL COMPARISON OF DIFFERENT ALGORITHMS FOR BASE CASE AND CONTINGENCY CASES

\begin{tabular}{|c|c|c|c|c|c|c|c|c|c|}
\hline \multirow[b]{2}{*}{ Cost (\$/h) } & \multicolumn{3}{|c|}{ Base case } & \multicolumn{3}{|c|}{ Line outage between buses 1-2 } & \multicolumn{3}{|c|}{ Line outage between buses 2-5 } \\
\hline & $\begin{array}{c}\text { Proposed } \\
\text { hybrid } \\
\text { method }\end{array}$ & APO & PSO & $\begin{array}{c}\text { Proposed } \\
\text { hybrid } \\
\text { method }\end{array}$ & APO & PSO & $\begin{array}{c}\text { Proposed } \\
\text { hybrid } \\
\text { method }\end{array}$ & APO & PSO \\
\hline Best & 576.62 & 576.73 & 577.32 & 603.90 & 604.92 & 605.10 & 593.98 & 594.07 & 596.25 \\
\hline Worst & 576.75 & 576.83 & 578.08 & 604.61 & 605.81 & 609.42 & 594.29 & 596.54 & 598.71 \\
\hline Mean & 576.66 & 576.78 & 277.41 & 604.28 & 605.21 & 607.65 & 594.16 & 595.22 & 597.36 \\
\hline $\begin{array}{l}\text { Standard } \\
\text { deviation }\end{array}$ & 0.039642 & 0.040029 & 0.538858 & 0.360026 & 0.383541 & 1.649737 & 0.116148 & 1.220495 & 0.792447 \\
\hline P-values & NA & $2.14 \mathrm{e}-04$ & $1.32 \mathrm{e}-04$ & NA & $1.28 \mathrm{e}-04$ & $1.29 \mathrm{e}-04$ & NA & $3.86 \mathrm{e}-04$ & $1.28 \mathrm{e}-04$ \\
\hline
\end{tabular}

TABLE VI. NEW ENGLAND 39-BUS SYSTEM: OPTIMAL GENERATION (MW) FOR BASE CASE

\begin{tabular}{|c|c|c|c|}
\hline $\begin{array}{c}\text { Generator bus } \\
\text { number }\end{array}$ & $\begin{array}{c}\text { Proposed } \\
\text { hybrid method }\end{array}$ & APO & PSO \\
\hline G30 & 247.44 & 256.74 & 262.18 \\
\hline G31 & 560.07 & 545.76 & 650.00 \\
\hline G32 & 653.84 & 637.88 & 678.27 \\
\hline G33 & 654.41 & 600.59 & 387.71 \\
\hline G34 & 498.45 & 476.38 & 556.61 \\
\hline G35 & 673.97 & 615.86 & 750.00 \\
\hline G36 & 528.48 & 623.74 & 673.89 \\
\hline G37 & 542.59 & 530.83 & 423.82 \\
\hline G38 & 841.17 & 856.63 & 747.34 \\
\hline G39 & 940.55 & 995.39 & 994.64 \\
\hline Fuel cost $(\$ / h)$ & 60917.68 & 60999.79 & 61165.77 \\
\hline CPU time $(\mathrm{s})$ & 134.40 & 137.80 & 142.40 \\
\hline
\end{tabular}

TABLE VII. DYNAMIC CONTINGENCY RANKING FOR 39-BUS SYSTEM

\begin{tabular}{|c|c|c|c|}
\hline $\begin{array}{c}\text { Faulted bus } \\
\text { number }\end{array}$ & $\begin{array}{c}\text { Line outage } \\
\text { between buses }\end{array}$ & $\begin{array}{c}\text { Transient Stability } \\
\text { Index (TSI) }\end{array}$ & Rank \\
\hline 27 & $17-27$ & -90.83 & 1 \\
\hline 5 & $4-5$ & -88.92 & 2 \\
\hline 17 & $16-17$ & -88.78 & 3 \\
\hline 10 & $10-13$ & -86.78 & 4 \\
\hline 8 & $8-9$ & -85.94 & 5 \\
\hline
\end{tabular}

The convergence plots of the proposed HPSO-APO, PSO and APO algorithms for the both contingency scenarios are shown in Figures 9 and 10. As shown, the proposed HPSOAPO method has quite faster convergence characteristics compared to existing reported methods. The proposed hybrid algorithm integrates the strength of both algorithms to get a balance between exploration and exploitation. The relative rotor angles obtained by the proposed HPSO-APO and reported methods are shown in Figure 9 (a, b). This confirms the relative rotor angles have Not violated their maximum limits during the alleviation of contingency. Hence, the system is dynamically secured after the rescheduling of active power outputs during the contingency scenario. The CPU time for completion of hundred iterations of the proposed hybrid algorithm for both the cases is tabulated in Tables VI and VIII. It shows that the proposed HPSO-APO method is faster compared to the standard APO and PSO methods. The performance measure (mean and standard deviation) and statistical results (P-values) comparison of the proposed HPSO-APO as well as standard APO and PSO algorithms for both base case and contingency cases are tabulated in Table IX. The results indicate that the proposed HPSO-APO algorithm achieves the statistically best final accuracy over standard APO and PSO algorithms.

TABLE VIII. NEW ENGLAND 39-BUS SYSTEM: OPTIMAL RESCHEDULING OF GENERATION (MW) FOR CONTINGENCY CASE

\begin{tabular}{|c|c|c|c|c|c|c|}
\hline \multirow{3}{*}{$\begin{array}{c}\text { Generator bus } \\
\text { number }\end{array}$} & \multicolumn{6}{|c|}{ Line outage between buses } \\
\hline & \multicolumn{2}{|c|}{ Proposed hybrid method } & \multicolumn{2}{|c|}{ APO } & \multicolumn{2}{|c|}{ PSO } \\
\hline & $17-27$ & $4-5$ & $17-27$ & $4-5$ & $17-27$ & $4-5$ \\
\hline G30 & 238.87 & 275.02 & 231.35 & 151.37 & 255.20 & 202.52 \\
\hline G31 & 541.74 & 550.20 & 544.87 & 460.21 & 430.39 & 374.84 \\
\hline G32 & 653.72 & 628.50 & 692.26 & 489.19 & 589.12 & 650.90 \\
\hline G33 & 648.93 & 609.63 & 623.85 & 715.13 & 659.12 & 750.00 \\
\hline G34 & 483.92 & 456.97 & 505.35 & 546.79 & 474.14 & 502.86 \\
\hline G35 & 697.01 & 750.00 & 615.82 & 745.53 & 711.40 & 644.71 \\
\hline G36 & 565.44 & 555.15 & 557.19 & 750.00 & 637.58 & 680.30 \\
\hline G37 & 530.09 & 502.31 & 579.45 & 548.52 & 608.21 & 477.18 \\
\hline G38 & 804.45 & 900.00 & 718.25 & 864.54 & 832.05 & 900.00 \\
\hline G39 & 975.22 & 914.74 & 1067.05 & 885.02 & 949.12 & 965.77 \\
\hline Fuel cost $(\$ / h)$ & 60964.60 & 61151.16 & 61055.45 & 61201.75 & 61250.78 & 61373.37 \\
\hline CPU time (s) & 182.35 & 185.26 & 192.89 & 193.25 & 210.78 & 212.65 \\
\hline
\end{tabular}



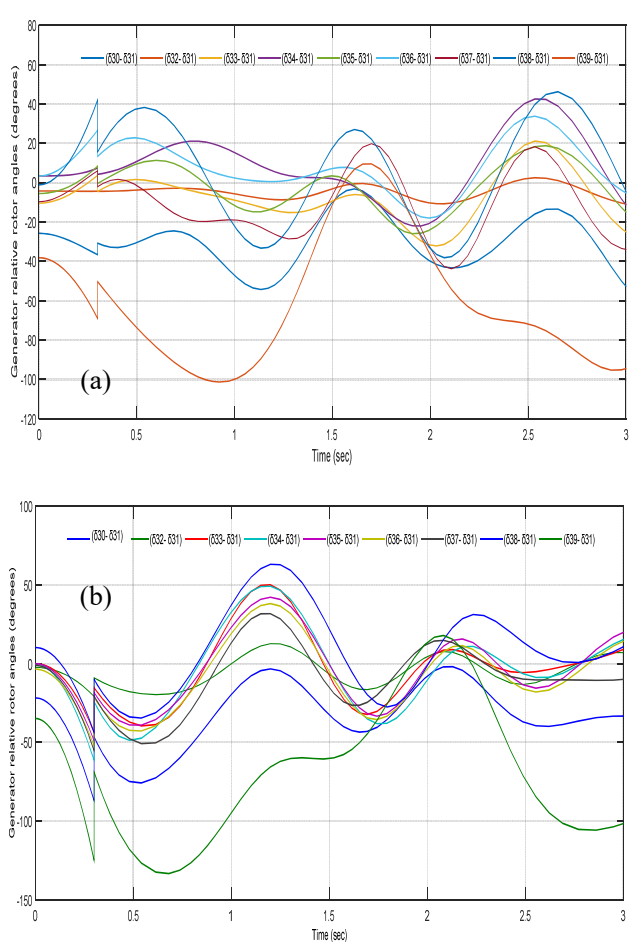

Fig. 8. Generator relative rotor angles for 39-bus system - proposed hybrid algorithm (a) Contingency-1 (between buses 17-27) (b) Contingency-2 (between buses 4-5)

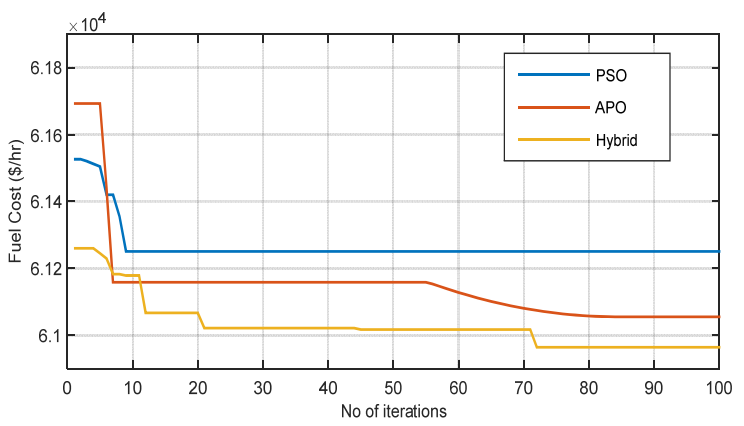

Fig. 9. Convergence characteristic of contingency-1 (between buses $17-$ 27) for 39-bus system.

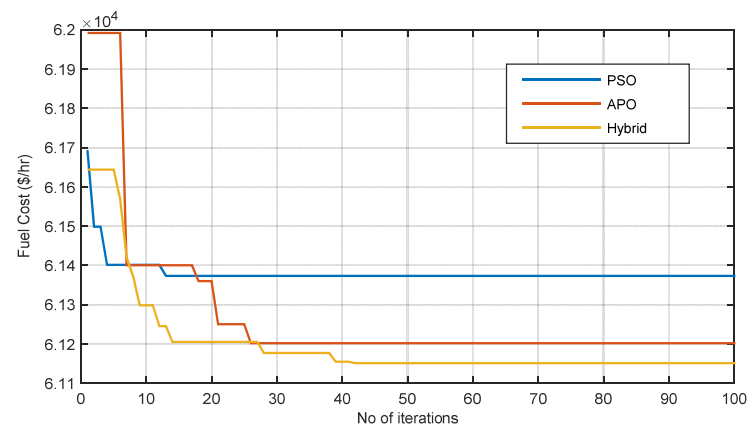

Fig. 10. Convergence characteristic of contingency-2 (between buses 4-5) for 39-bus system.

TABLE IX. NEW ENGLAND 39-BUS SYSTEM: PERFORMANCE AND STATISTICAL COMPARISON OF DIFFERENT ALGORITHMS FOR BASE CASE AND CONTINGENCY CASES

\begin{tabular}{|c|c|c|c|c|c|c|c|c|c|}
\hline \multirow[b]{2}{*}{ Cost (\$/h) } & \multicolumn{3}{|c|}{ Base case } & \multicolumn{3}{|c|}{ Line outage between buses 17-27 } & \multicolumn{3}{|c|}{ Line outage between buses 4-5 } \\
\hline & $\begin{array}{c}\text { Proposed } \\
\text { hybrid method }\end{array}$ & APO & PSO & $\begin{array}{l}\text { Proposed hybrid } \\
\text { method }\end{array}$ & APO & PSO & $\begin{array}{l}\text { Proposed hybrid } \\
\text { method }\end{array}$ & APO & PSO \\
\hline Best & 60917.8 & 60999.7 & 61165.7 & 60964.6 & 61055.4 & 61250.7 & 61151.1 & 61201.7 & 61373.5 \\
\hline Worst & 60946.2 & 61057.5 & 61230.2 & 60990.2 & 61109.8 & 61315.1 & 61182.1 & 61373.3 & 61404.1 \\
\hline Mean & 60928.5 & 61027.5 & 61205.7 & 60979.0 & 61070.7 & 61263.9 & 61162.9 & 61287.4 & 61391.0 \\
\hline Std & 11.25619 & 23.68506 & 27.75061 & 11.80751 & 21.37535 & 30.23327 & 13.26959 & 17.31354 & 16.43638 \\
\hline P-values & NA & $1.884 \mathrm{e}-04$ & $1.872 \mathrm{e}-04$ & NA & $1.92 \mathrm{e}-04$ & $1.89 \mathrm{e}-04$ & NA & $1.23 \mathrm{e}-04$ & $1.23 \mathrm{e}-04$ \\
\hline
\end{tabular}

\section{CONCLUSIONS}

A novel hybrid PSO-APO algorithm is employed in this paper to solve the dynamic security constrained optimal power flow (DSCOPF) problem in order to enhance system security. The proposed hybrid optimization algorithm integrates the strengths of both algorithms to get a balance between exploration and exploitation. The proposed method is demonstrated on standard test systems like the IEEE sixgenerator, 30-bus system and the New England ten-generator, 39-bus system. Simulation results revealed that the proposed hybrid PSO-APO algorithm is shown to be superior and more robust compared to the standard APO and PSO algorithms in terms.

\section{REFERENCES}

[1] B. Stott, O. Alsac, A. J. Monticelli, "Security analysis and optimization", Proceedings of the IEEE, Vol. 75, No. 12, pp. 1623-1644, 1987

[2] K. Morison, W. Lei, P. Kundur, "Power system security assessment", IEEE Power and Energy Magazine, Vol. 2, No. 5, pp. 30-39, 2004
[3] Y. Zhang, L. Wehenkel, P. Rousseaux, M. Pavella, "SIME: A hybrid approach to fast transient stability assessment and contingency selection", International Journal of Electrical Power \& Energy Systems, Vol. 19, No. 3, pp. 195-208,. 1997

[4] F. Allella, D. Lauria, "Fast optimal dispatch with global transient stability constraint", IEEE Proceedings-Generation, Transmission and Distribution, Vol. 148, No. 5, pp. 471-476, 2001

[5] Y. Yuan, J. Kubokawa, H. Sasaki, "A solution of optimal power flow with multicontingency transient stability constraints", IEEE Transactions on Power Systems, Vol. 18, No. 3, pp. 1094-1102, 2003

[6] A. Monticelli, M. V. F. Pereira, S. Granville, "Security-Constrained Optimal Power Flow with Post-Contingency Corrective Rescheduling", IEEE Transactions on Power Systems, Vol. 2, No. 1, pp. 175-180, 1987

[7] C. A. Roa-Sepulveda, B. J. Pavez-Lazo, "A solution to the optimal power flow using simulated annealing", International Journal of Electrical Power \& Energy Systems, Vol. 25, No. 1, pp. 47-57, 2003

[8] S. R. Paranjothi, K. Anburaja, "Optimal Power Flow Using Refined Genetic Algorithm", Electric Power Components and Systems, Vol. 30, No. 10, pp. 1055-1063, 2002

[9] K. Vaisakh, L. R. Srinivas, "Evolving ant direction differential evolution for OPF with Non-smooth cost functions", Engineering Applications of Artificial Intelligence, Vol. 24, No. 3, pp. 426-436, 2011 
[10] H. R. Cai, C. Y. Chung, K. P. Wong, "Application of differential eVolution algorithm for transient stability constrained optimal power flow", IEEE Transactions on Power Systems, Vol. 23, No. 2, pp. 719728, 2008

[11] J. Yuryevich, Kit Po Wong, "Evolutionary programming based optimal power flow algorithm", IEEE Transactions on Power Systems, Vol. 14, No. 4, pp. 1245-1250, 1999

[12] M. A. Abido, "Optimal power flow using particle swarm optimization", International Journal of Electrical Power \& Energy Systems, Vol. 24, No. 7, pp. 563-571, 2002

[13] N. Mo, Z. Y. Zou, K. W. Chan, T. Y. G. Pong, "Transient stability constrained optimal power flow using particle swarm optimisation", IET Generation, Transmission \& Distribution, Vol. 1, No. 3, pp. 476-483, 2007

[14] L. Slimani, T. Bouktir, "Economic power dispatch of power systems with pollution control using artificial bee colony optimization", Turkish Journal Of Electrical Engineering \& Computer Sciences, Vol. 21, No. 2, pp. $1515-1527,2013$

[15] S. W. Xia, B. Zhou, K. W. Chan, Z. Z. Guo, "An improved GSO method for discontinuous non-convex transient stability constrained optimal power flow with complex system model", International Journal of Electrical Power \& Energy Systems, Vol. 64, pp. 483-492, 2015

[16] K. Ayan, U. Kilic, B. Barakli, "Chaotic artificial bee colony algorithm based solution of security and transient stability constrained optimal power flow", International Journal of Electrical Power \& Energy Systems, Vol. 64, pp. 136-147, 2015

[17] K. Teeparthi, D. M. ViNod Kumar, "Grey wolf optimization algorithm based dynamic security constrained optimal power flow", National Power Systems Conference, Bhubaneswar, pp. 1-6, 2016

[18] A. Trivedi, D. Srinivasan, S. Biswas, T. Reindl, "Hybridizing genetic algorithm with differential eVolution for solving the unit commitment scheduling problem", Swarm and Evolutionary Computation, Vol. 23, pp. 50-64, 2015

[19] M. Mehdinejad, B. Mohammadi-Ivatloo, R. Dadashzadeh-Bonab, K. Zare, "Solution of optimal reactive power dispatch of power systems using hybrid particle swarm optimization and imperialist competitive algorithms", International Journal of Electrical Power \& Energy Systems, Vol. 83, pp. 104-116, 2016

[20] J. Polprasert, W. Ongsakul, V. N. Dieu, "Optimal Reactive Power Dispatch Using Improved Pseudo-gradient Search Particle Swarm Optimization", Electric Power Components and Systems, Vol. 44, No. 5, pp. $518-532,2016$
[21] W. Ongsakul, P. Bhasaputra, "Optimal power flow with FACTS devices by hybrid TS/SA approach", International Journal of Electrical Power and Energy Systems, Vol. 24, No. 10, pp. 851-857, 2002

[22] K. Teeparthi, D. M. ViNod Kumar, "Security-constrained optimal power flow with wind and thermal power generators using fuzzy adaptive artificial physics optimization algorithm", Neural Computing and Applications, 2016

[23] M. Ghasemi, S. Ghavidel, S. Rahmani, A. Roosta, H. Falah, "A Novel hybrid algorithm of imperialist competitive algorithm and teaching learning algorithm for optimal power flow problem with non-smooth cost functions", Engineering Applications of Artificial Intelligence, Vol. 29, pp. 54-69, 2014

[24] M. Ghasemi, M. Taghizadeh, S. Ghavidel, J. Aghaei, A. Abbasian, "Solving optimal reactive power dispatch problem using a novel teaching-learning-based optimization algorithm", Engineering Applications of Artificial Intelligence, Vol. 39, pp. 100-108, 2015

[25] K. Tangpatiphan, A. Yokoyama, "Adaptive EVolutionary Programming with Neural Network for Transient Stability Constrained Optimal Power Flow", 15th International Conference on Intelligent System Applications to Power Systems, pp. 1-6, 2009

[26] C. Fu, A. Bose, "Contingency ranking based on severity indices in dynamic security analysis", IEEE Transactions on Power Systems, Vol. 14, No. 3, pp. 980-985, 1999

[27] J. M. Gimenez Alvarez, P. E. Mercado, "Online Inference of the Dynamic Security Level of Power Systems Using Fuzzy Techniques", IEEE Transactions on Power Systems, Vol. 22, No. 2, pp. 717-726, 2007

[28] C. Liu, K. Sun, Z. H. Rather, Z. Chen, C. L. Bak, P. Thogersen, P. Lund, "A Systematic Approach for Dynamic Security Assessment and the Corresponding Preventive Control Scheme Based on Decision Trees", IEEE Transactions on Power Systems, Vol. 29, No. 2, pp. 717-730, 2014

[29] R. Eberhart, J. Kennedy, "A new optimizer using particle swarm theory", Sixth International Symposium on Micro Machine and Human Science, pp. 39-43, 1995

[30] L. Xie, J. Zeng, Z. Cui, "General framework of Artificial Physics Optimization Algorithm", World Congress on Nature \& Biologically Inspired Computing , pp. 1321-1326, 2009

[31] E. G. Talbi, "A taxonomy of hybrid metaheuristics", Journal of Heuristics, Vol. 8, No. 5, pp. 541-564, 2002

[32] R. D. Zimmerman, C. E. Murillo-Sanchez, Matpower: a matlab power system simulation package, available at http://www.pserc.cornell.edu/ matpower/, 2005 